\title{
Assessment of the Tear Evaporation Rate in Chronic Smokers Using Delfin VapoMeter
}

\author{
Saud Ahmed Alanazi", Ali Abusharha, Raied Fagehi, Ali Mazyed Alsaqr, \\ Gamal Abdel-Rahman El-Hiti", Raed Ali Alahmari, Faisal Abdullah Alenazi, \\ Khalid Mansour Alnassar, Ali Mohammed Masmali
}

Department of Optometry, College of Applied Medical Sciences, King Saud University, Riyadh, Saudi Arabia

\section{Email address:}

saaalanazi@ksu.edu.sa (S. A. Alanazi), aabusharha@ksu.edu.sa (A. Abusharha),rfagehi@ksu.edu.sa (R. Fagehi), aalsaqr@ksu.edu.sa (A. M. Alsaqr), gelhiti@ksu.edu.sa (G. Abdel-Rahman El-Hiti), ra.alahmari1@gmail.com (R. A. Alahmari), alenazifaisala@gmail.com (F. A. Alenazi),khalidm.f.alnassar@gmail.com (K. M. Alnassar), amasmali@ksu.edu.sa (A. M. Masmali) *Corresponding author

\section{To cite this article:}

Saud Ahmed Alanazi, Ali Abusharha, Raied Fagehi, Ali Mazyed Alsaqr, Gamal Abdel-Rahman El-Hiti, Raed Ali Alahmari, Faisal Abdullah Alenazi, Khalid Mansour Alnassar, Ali Mohammed Masmali. Assessment of the Tear Evaporation Rate in Chronic Smokers Using Delfin VapoMeter. International Journal of Ophthalmology \& Visual Science. Vol. 4, No. 2, 2019, pp. 37-41. doi: 10.11648/j.ijovs.20190402.12

Received: June 8, 2019; Accepted: July 4, 2019; Published: July 16, 2019

\begin{abstract}
Background: Smoking cigarettes is associated with many chronic illnesses such as cancer, heart diseases, and cataract. In addition, smokers are more likely to develop dry eye symptoms compared with nonsmokers. Purpose: To assess the tear evaporation rate in chronic smokers using a VapoMeter. Materials and Method: This observational, case-control and nonrandomized study included one hundred and twenty male smokers that ranged in age from 18 to 43 years (mean $\pm \mathrm{SD}=$ $25.4 \pm 5.8$ years). An age (18-43 years) matching control group (120 male subjects), with a mean age of $26.1 \pm 5.2$ years participated in the study. Each participant completed the ocular surface disease index dry eye questionnaire, then a VapoMeter was used to determine the tear evaporation rate. Result: Significant (Kolmogorov-Smirnov test; $p<0.05$ ) differences were found between the average scores collected from the ocular surface disease index and the tear evaporation rate measurements within the smokers and nonsmokers groups. The average tear evaporation rate was significantly $(p<0.05)$ higher in the study group [median (interquartile range; IQR) $=37.7(59.3) \mathrm{g} / \mathrm{m}^{2} \mathrm{~h}$ ] compared with that obtained in control group [15.4 (13.1) $\left.\mathrm{g} / \mathrm{m}^{2} \mathrm{~h}\right]$. Moreover, the average score from the ocular surface disease index in smokers was significantly $(p<0.05)$ higher $[15.4$ (13.1)] compared with that obtained in the control group [5.4 (5.5)]. Conclusion: Smokers have significant higher tear evaporation rates compared with nonsmokers and normal eye subjects. Clearly, VapoMeter can be used as a reliable tool to assess the eye dryness due to excessive evaporation of tears. Smoking is a risk factor for cancer, heart diseases, and cataract. In addition, smoking is a risk factor for eye dryness and contributes to evaporative dry eye disease, more likely due to the disturbance in the non-polar lipid layer within the tear film. Lipid-rich eye drops could be used to manage dry eye symptoms in smoker subjects. Moreover, smoking cessation remains the single most effective prophylactic measure to avoid dry eye symptoms.
\end{abstract}

Keywords: Smokers, Dry Eye, Tear Evaporation Rate, Evaporative Dry Eye, VapoMeter

\section{Introduction}

Tobacco consumption has increased over the years and has become a major public concern. Tobacco contains many toxic chemicals and, as a result, is responsible for the death of more than eight million globally every year $[1,2]$. The consumption of tobacco is declining in Europe and North
America and slightly increasing in Eastern Europe and Asia. The number of smokers is estimated to be in the range of 1.1 billion in which the majority of them live in poorer countries [1]. Cigarettes are the most common method of tobacco consumption. Smoking is a risk factor for various chronic illnesses, such as cancer, heart diseases, and cataract [3-8]. In addition, association between smoking and dry eye 
symptoms has been suggested [9-12]. Smokers can develop dry eye symptoms by a factor of 1.44 compared with nonsmokers [13].

Dry eye syndrome is a common ocular disease that affects around $5-35 \%$ of the world population $[14,15]$. Evaporative and aqueous deficient dry eye are very common resulting mainly due to the dysfunctions of the Meibomian and lacrimal glands, respectively [16]. Eye dryness leads to a discomfort that affects the quality of life. Such discomfort can be evaluated using dry eye questionnaires (e.g. the ocular surface disease index, OSDI) [17]. Several diagnostic tests have been used to the assess eye dryness in terms of the quality and quantity of tears [18-24].

The measurement of tear evaporation rate (TER) can provide useful information about the tear film stability and degree of eye dryness [25]. The TER test is a noninvasive and valuable technique to assess tear dynamics and can be used to differentiate between dry eye symptoms due to either aqueous or lipid tear deficiency [26, 27]. For normal eye, the TER is the range of $19-21 \mathrm{~g} / \mathrm{m}^{2} \mathrm{~h}(0.04-0.07 \mu \mathrm{l} / \mathrm{min})$ [28]. There are various techniques that can be used to measure the TER, such as infrared thermography which has been used to measure TER and monitors its variation over time [29]. Spectral interferometry is used to measure the precorneal tear film thickness and its thinning between blinks [30], while VapoMeter is a dermatology device used to measure the trans-epidermal water loss and evaporation rate [31]. The current study assessed the TER among smokers using Delfin VapoMeter, a light, portable device that does not need to be calibrated daily, can be used in all angles, is not sensitive to ambient airflows, and involves only a few seconds to perform the measurement [32]. Delfin VapoMeter is currently used efficiently to assess the TER in subjects with thyroid gland disorders [32].

\section{Materials and Methods}

This observational, case-control and non-randomized study included one hundred and twenty male smokers. The age of the smoker subjects ranged from 18 to 43 years (mean \pm SD $=25.4 \pm 5.8$ years). In addition, an age (18-43 years) matching control group (120 male subjects), with an average of $26.1 \pm 5.2$ years, participated in the study. An informed written consent was obtained from each participant prior to conducting the study. The study was approved by the College of Applied Medical Science Ethics Committee and the participants were treated based on Helsinki Declaration [33]. The exclusion criteria included subjects having a risk factor for dry eye, contact lens wearers, those who had abnormalities in the eyelids, had undergone recent ocular surgeries, consumed medication, had diabetes, a high level of cholesterol, a high body mass index, thyroid disorders, and anemia.

The OSDI dry eye questionnaire was completed first by all participants in which a score of less than 13 was defined as a normal eye [17]. The measuement of TER using a VapoMeter (Delfin Technologies UK Limited, Surrey, UK) was performed three times with two readings obtained in each case. In the first reading, both eyes were opened and blinking normally, while, in the second reading, the test was conducted with both eyes closed. Two minutes were applied as a gap between tests. The TER was calculated by subtracting the reading when both eyes were closed from the reading where both eyes were opened so as to obtain the average. Evaporative dry eye condition was defined for a TER of more than $25 \mathrm{~g} / \mathrm{m}^{2} \mathrm{~h}[32,34]$. The TER tests were carried out in a room where the temperature $\left(22{ }^{\circ} \mathrm{C}\right)$ and humidity level (less than 35\%) were controlled.

The data were collected in Excel (Microsoft Corporation, Redmond, WA, USA) and were analyzed using the SPSS statistical software package (IBM, Armonk, NY, USA).

\section{Results}

The age was normally distributed (Kolmogorov-Smirnov test; $p>0.05)$ in smokers and nonsmoker groups and the average was presented as mean $\pm \mathrm{SD}$. The data obtained from the OSDI sheets and TER tests were abnormally distributed (Kolmogorov-Smirnov test; $p<0.05$ ) and the average was presented as median (interquartile ranges; IQR). The averages for the age, the OSDI scores and TER measurements are shown in Table 1 . The side-by-side boxplots for the OSDI and TER scores in the smoker and nonsmoker groups are shown in Figures 1 and 2, respectively.

Table 1. The averages for the age, OSDI scores, and TER measurements $(p<0.05)$.

\begin{tabular}{lll}
\hline Score & Smokers group $(\mathbf{n}=120)$ & nonsmoker group $(\mathbf{n}=120)$ \\
\hline Age $($ year $)$ & $25.4 \pm 5.8$ & $26.1 \pm 5.2$ \\
OSDI* & $18.8(8.8)$ & $5.4(5.5)$ \\
TER $(\mathrm{g} / \mathrm{m} 2 \mathrm{~h})^{*}$ & $37.7(59.3)$ & $15.4(13.1)$ \\
\hline
\end{tabular}

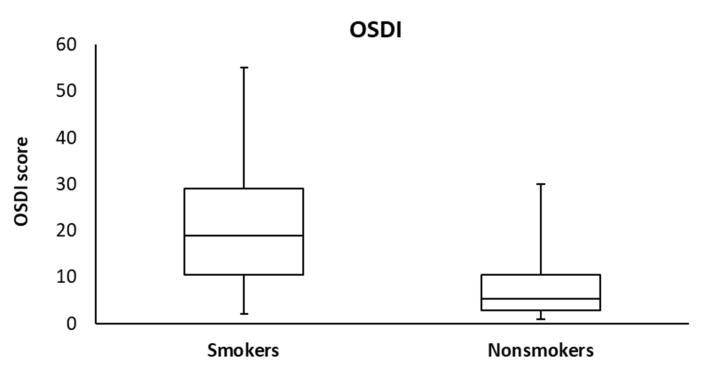

Figure 1. Side-by-side boxplots for the ocular surface disease index scores $(p<0.05)$.

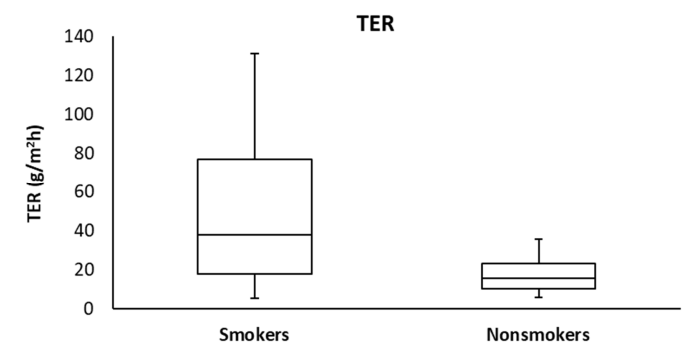

Figure 2. Side-by-side boxplots for tear evaporation rate measurements $(p<0.05)$. 
The average of TER was significantly (KolmogorovSmirnov test; $p<0.05)$ higher in smokers [median (interquartile range; IQR) $\left.=37.7(59.3) \mathrm{g} / \mathrm{m}^{2} \mathrm{~h}\right]$ compared with that obtained within control group [15.4 (13.1) $\left.\mathrm{g} / \mathrm{m}^{2} \mathrm{~h}\right]$. Moreover, the OSDI average score was significantly (Kolmogorov-Smirnov test; $p<0.05)$ higher [15.4 (13.1)] in smokers compared with nonsmokers [5.4 (5.5)]. The OSDI score ranged from 2.1 to 55.0 and from 1.0 to 30.0 for the smokers and nonsmokers groups, respectively. For smokers group, the TER scores ranged from 5.5 to $131.0 \mathrm{~g} / \mathrm{m}^{2} \mathrm{~h}$ and from 5.9 to $35.7 \mathrm{~g} / \mathrm{m}^{2} \mathrm{~h}$ for the control group. The TER measurements showed that 85 smokers $(70.8 \%)$ had higher reading compared with normal level, indicating a dry eye condition. Similarly, the OSDI scores showed that 82 smokers $(68.3 \%)$ indicated discomfort as a result of eye dryness. There was a medium correlation $(r=0.451 ; p=0.039)$ between the OSDI scores and TER measurements.

\section{Discussion}

The current study suggests an association between cigarette smoking and dry eye symptoms based on the OSDI scores and the TER test measurements. Such results are consistent with previously reported findings, but using a different tear evaporimeter. For example, the TER measured by a tear evaporimeter (KAO Corporation) among chronic smokers $(n=15)$ who consumed 20 cigarettes a day for long duration $(20$ years $)$ showed a significant $(p<0.001)$ increase in the TER scores, lipid layer interferometry measurements, and hemoglobin carbon dioxide level and a reduction in the tear break-up time (TBUT) scores [35]. In smokers, the average scores of TER was $7.7 \pm 0.2 \times 10^{-7} \mathrm{~g} / \mathrm{cm}^{2}$ per second compared with $2.5 \pm 0.9 \times 10^{-7} \mathrm{~g} / \mathrm{cm}^{2}$ per second among normal eye subjects [35]. However, there was no significant $(p>0.05)$ difference in the Schirmer's test scores between smokers and nonsmokers [35].

The tear film stability among healthy subjects exposed to cigarette smoke in a controlled environment was investigated [36]. The TER, TBUT, vital staining scores and tear lipid spread time in passive smokers were significantly $(p<0.05)$ worse compared with the scores obtained pre-exposure to cigarettes smoke [36]. For example, the average TER measured using a tear evaporimeter (KAO Corporation) was $1.8 \pm 1.2 \mathrm{~g} / \mathrm{cm}^{2}$ per second before exposure to smoke compared with $3.3 \pm 2.0 \mathrm{~g} / \mathrm{cm}^{2}$ per second after $5 \mathrm{~min}$ of smoke exposure [36]. Similar results were obtained among soft contact lens wearer who were exposed to passive cigarette smoke [37]. The TER was significantly $(p<0.05)$ higher in contact lens wearer compared with non-contact lens wearer after exposure to cigarette smoke [37].

Smoking had a negative effect on the tear film stability [9, 38-41]. For example, the study conducted on 30 smokers and 30 nonsmokers showed a significant difference in the McMonnies scores $(p=0.020)$, TBUT test scores $(p=0.036)$, and tear ferning (TF) test grades $(p=0.001)$ between smokers and nonsmokers [9]. Another study indicated that smokers $(n=50)$ had significantly $(p<0.001)$ lower scores from the
TBUT and Schirmer tests compared with nonsmokers [38]. The degree of dry eye severity was found to be dependent on the number of cigarettes smoked daily [38]. In addition, the OSDI scores were found to be significantly $(p<0.001)$ higher among female smokers $(n=63)$ compared with nonsmokers [39].

A study conducted on sixty (33 male and 27 female) heavy smokers who had smoked cigarettes for at least five years showed significant $(p<0.05)$ differences in the scores obtained from the TBUT, conjunctival sensitivity, and central corneal sensitivity compared with those obtained among nonsmokers [42]. For the Schirmer test and goblet cell densities, there were no significant $(p>0.05)$ differences between smoker and nonsmoker groups [42]. Smoking seems to affect the spreading of lipids layer since normal subjects showed smooth spread of lipids layer (grade 1 and 2) compared with smokers (grade 3 to 4). A higher grade of lipids is an indication of dry eye symptoms [42]. It seems likely that smoking tends to damage the precorneal tear film lipids layer through lipid peroxidation due to generation of free radicals [42]. The tear film polar lipids layer, which contains wax, cholesterol esters, and triglycerides, acts as an interface between the air and tear film and tends to reduce the TER significantly [43]. It has been suggested that the thickness of the lipids layer has an inverse relationship with the TER [43] with the disturbance in the lipids layer of tear film believed to be responsible for the high TER among smokers [43]. The interaction between aqueous and mucin layers acts as a barrier for evaporation of tears [43]. In contrast, another study suggested that the thickness of tear film lipids layer does not decrease in smokers, but the tear thinning rate increases [44].

The study has some limitations in which the harsh environmental factors, such as high degree of humidity and temperature, that any of the subjects might experience just before the measurements took place was not assessed. In addition, the subjects were only male and from Riyadh City. Therefore, a future study is still needed to overcome the limitations associated with the current study and to prove further the association between smoking and dry eye symptoms.

\section{Conclusion}

Smokers have significant higher tear evaporation rates compared with nonsmokers and normal eye subjects. Clearly, VapoMeter can be used as a reliable tool to assess the eye dryness due to excessive evaporation of tears. Smoking is a risk factor for cancer, heart diseases, and cataract. In addition, smoking is a risk factor for eye dryness and contributes to evaporative dry eye disease, more likely due to the disturbance in the non-polar lipid layer within the tear film. Lipid-rich eye drops could be used to manage dry eye symptoms in smoker subjects. Moreover, smoking cessation remains the single most effective prophylactic measure to avoid dry eye symptoms. 


\section{Acknowledgements}

We thank King Saud University for the continued support.

\section{Conflict of Interest}

All the authors do not have any possible conflicts of interest.

\section{References}

[1] World Health Organization. Tobacco. https://www.who.int/news-room/fact-sheets/detail/tobacco [accessed 03 June 2019]

[2] Smith CJ, Hansch C. The relative toxicity of compounds in mainstream cigarette smoke condensate. Food Chem Toxicol 2000; 38 (7): 637-646. doi: 10.1016/S0278-6915(00)00051$\mathrm{X}$

[3] O'Keeffe LM, Taylor G, Huxley RR, Mitchell P, Woodward $\mathrm{M}$, Peters SAE. Smoking as a risk factor for lung cancer in women and men: a systematic review and meta-analysis. BMJ Open. 2018; 8 (10): e021611. doi: 10.1136/bmjopen-2018021611

[4] Reitsma MB, Fullman N, Ng M, et al. Smoking prevalence and attributable disease burden in 195 countries and territories, 1990-2015: a systematic analysis from the Global Burden of Disease Study 2015. Lancet. 2017; 389 (10082): 1885-1906. doi: 10.1016/S0140-6736(17)30819-X

[5] Forouzanfar MH, Afshin A, Alexander LT, et al. Global, regional, and national comparative risk assessment of 79 behavioural, environmental and occupational, and metabolic risks or clusters of risks, 1990-2015: a systematic analysis for the Global Burden of Disease Study 2015. Lancet. 2016; 388 (10053): 1659-1724. doi: 10.1016/S01406736(16)31679-8

[6] Papadopoulos A, Guida F, Leffondré K, Cénée S, Cyr D, Schmaus A, Radoï L, Paget-Bailly S, Carton M, Menvielle G, Woronoff AS, Tretarre B, Luce D, Stücker I. Heavy smoking and lung cancer: Are women at higher risk? Result of the ICARE study. Br J Cancer. 2014; 110 (5): 1385-1391. doi: 10.1038/bjc.2013.821

[7] Bernhard D. Cigarette Smoke Toxicity: Linking Individual Chemicals to Human Diseases, Wiley-VCH, Singapore, 2011.

[8] Kelly SP, Thornton J, Edwards R, Sahu A, Harrison R. Smoking and cataract: review of causal association. J Cataract Refract Surg. 2005; 31 (12): 2395-404. doi: 10.1016/j.jcrs.2005.06.039

[9] Masmali A, Shehri A, Alanazi S, Abusharaha A, Fagehi R, ElHiti G. Assessment of tear film quality among smokers using tear ferning patterns. J Ophthalmol. 2016; 2016: 8154315. doi: $10.1155 / 2016 / 8154315$

[10] Xu L, Zhang W, Zhu XY, Suo T, Fan XQ, Fu Y. Smoking and the risk of dry eye: a Meta-analysis. Int J ophthalmol. 2016; 9 (10): 1480-1486. doi: 10.18240/ijo.2016.10.19

[11] Chia EM, Mitchell P, Rochtchina E, Lee AJ, Maroun R, Wang JJ. Prevalence and associations of dry eye syndrome in an older population: The Blue Mountains eye study. Clin Exp Ophthalmol. 2003; 31 (3): 229-232. doi: 10.1046/j.1442-

\section{$9071.2003 .00634 . \mathrm{x}$}

[12] Satici A, Bitiren M, Ozardali I, Vural H, Kilic A, Guzey M. The effects of chronic smoking on the ocular surface and tear characteristics: a clinical, histological and biochemical study. Acta Ophthalmol Scand. 2003; 81 (6): 583-587. doi: 10.1111/j.1395-3907.2003.00158.x

[13] Lee AJ, Lee J, Saw SM, Gazzard G, Koh D, Widjaja D, Tan DT. Prevalence and risk factors associated with dry eye symptoms: a population based study in Indonesia. $\mathrm{Br} \mathrm{J}$ Ophthalmol. 2002; $86 \quad$ (12): 1347-1351. doi: 10.1136/bjo.86.12.1347

[14] The epidemiology of dry eye disease: report of the Epidemiology Subcommittee of the International Dry Eye WorkShop (2007). Ocul Surf. 2007; 5 (2): 93-107. doi: 10.1016/S1542-0124(12)70082-4

[15] Craig JP, Nelson JD, Azar DT, Belmonte C, Bron AJ, Chauhan SK, de Paiva CS, Gomes JAP, Hammitt KM, Jones L, Nichols JJ, Nichols KK, Novack GD, Stapleton FJ, Willcox MDP, Wolffsohn JS, Sullivan DA. TFOS DEWS II Report Executive Summary. Ocul Surf. 2017; 15 (4): 802-812. doi: 10.1016/j.jtos.2017.08.003

[16] Craig JP, Nichols KK, Akpek EK, Caffery B, Dua HS, Joo CK, Liu Z, Nelson JD, Nichols JJ, Tsubota K, Stapleton F. TFOS DEWS II Definition and Classification Report. Ocul $\begin{array}{lllll}\text { Surf. } 2017 ; \quad 15 & \text { (3): 276-283. doi: }\end{array}$ 10.1016/j.jtos.2017.05.008

[17] Schiffman RM, Christianson MD, Jacobsen G, Hirsch JD, Reis BL. Reliability and validity of the Ocular Surface Disease Index. Arch Ophthalmol. 2000; 118 (5): 615-621. doi: 10.1001/archopht.118.5.615

[18] Masmali A, Alqahtani TA, Alharbi A, El-Hiti GA. Comparative study of repeatability of phenol red thread test versus Schirmer's test in normal adults in Saudi Arabia. Eye Contact Lens. 2014; 40 (3): 127-131. doi: 10.1097/ICL.0000000000000025

[19] Masmali A, Alrabiah S, Alharbi A, El-Hiti GA, Almubrad T. Investigation of tear osmolarity using the TearLab ${ }^{\mathrm{TM}}$ osmolarity system in normal adults in Saudi Arabia. Eye $\begin{array}{llll}\text { Contact Lens. 2014; } 40 & \text { (2): 74-78. doi: }\end{array}$ 10.1097/ICL.0000000000000002

[20] Masmali AM, Al-Qhtani S, Al-Gasham TM, El-Hiti GA, Purslow C, Murphy PJ. Application of a new grading scale for tear ferning in non-dry eye and dry eye subjects. Cont Lens Anterior Eye. 2015; 38 (1): 39-43. doi: 10.1016/j.clae.2014.09.007

[21] Masmali AM, Maeni YA, El-Hiti GA, Murphy PJ, Almubrad $\mathrm{T}$. Investigation of ocular tear ferning in controlled and uncontrolled diabetic subjects. Eye Contact Lens. 2018; 44 (Suppl 2): S70-S75. doi: 10.1097/ICL.0000000000000419

[22] Masmali AM, Alotaibi AG, Alanazi SA, Fagehi R, Abusharaha A, El-Hiti GA. The acute effect of a single dose of green tea on the quality and quantity of tears in normal eye subjects. Clin Ophthalmol. 2019; 13: 605-610. doi: 10.2147/OPTH.S201127

[23] Masmali AM, Alanazi SA, Almagren B, El-Hiti GA. Assessment of the tear film in normal eye subjects after consumption of a single dose of hot peppermint drink. Clin Optom. 2019; 11: 39-45. doi: 10.2147/OPTO.S206904 
[24] Alanazi SA, El-Hiti GA, Al-Baloud AA, Alfarhan MI, AlShahrani A, Albakri AA, Alqahtani S, Masmali AM. Effects of short-term oral vitamin A supplementation on the ocular tear film in patients with dry eye. Clin Ophthalmol. 2019; 13: 599604. doi: 10.2147/OPTH.S198349

[25] Wong S, Murphy PJ, Jones L. Tear evaporation rates: what does the literature tell us? Cont Lens Anterior Eye. 2018; 41 (3): 297-306. doi: 10.1016/j.clae.2017.12.003

[26] Shimazaki J, Sakata M, Tsubota, K. Ocular surface changes and discomfort in patients with meibomian gland dysfunction. Arch Ophthalmol. 1995; 113 (10): 1266-1270. doi: 10.1001/archopht.1995.01100100054027

[27] Tsubota, K, Yamada, M. Tear evaporation from the ocular surface. Invest Ophthalmol Vis Sci. 1992; 33: 2942-2950

[28] Tomlinson A, Doane MG, McFadyen A. Inputs and outputs of the lacrimal system: review of production and evaporative loss. Ocul Surf. 2009; 7 (4): 186-198. doi: 10.1016/S15420124(12)70186-6

[29] Tan JH, Ng EY, Acharya UR. Evaluation of tear evaporation from ocular surface by functional infrared thermography. Mid Phys. 2010; 37 (11): 5565-6112. doi: 10.1118/1.3495540

[30] Nichols J, Mitchell G, King-Smith P. Thinning rate of the precorneal and prelens tear films. Invest Ophthalmol Vis Sci. 2005; 46 (7): 2353-2361. doi: 10.1167/iovs.05-0094

[31] Rohit A, Ehrmann K, Naduvilath T, Willcox M, Stapleton F. Validating a new device for measuring tear evaporation rates. Ophthalmic Physiol Opt. 2014; 34 (1): 53-62. doi: 10.1111/opo.12096

[32] Abusharaha A, Alturki AA, Alanazi SA, Fagehi R, Al-Johani N, El-Hiti GA, Masmali AM. An assessment of the tear evaporation rate in thyroid gland patients. Clin Ophthalmol. 2019; 13: 131-135. doi: 10.2147/OPTH.S188614

[33] World Medical Association Declaration of Helsinki: ethical principles for medical research involving human subjects. JAMA. 2013; 310 (20): 2191-2194. doi: 10.1001/jama.2013.281053

[34] Khanal S, Tomlinson A, Diaper CJ. Tear physiology of aqueous deficiency and evaporative dry eye. Optom Vis Sci. 2009; $86 \quad$ (11): $1235-1240 . \quad$ doi: 10.1097/OPX.0b013e3181bc63cc
[35] Matsumoto Y, Dogru M, Goto E, Sasaki Y, Inoue H, Saito I, Shimazaki J, Tsubota K. Alterations of the tear film and ocular surface health in chronic smokers. Eye. 2008; 22 (7): 961968. doi: $10.1038 /$ eye. 2008.78

[36] Rummenie VT, Matsumoto Y, Dogru M, Wang Y, Hu Y, Ward SK, Igarashi A, Wakamatsu T, Ibrahim O, Goto E, Luyten G, Inoue H, Saito I, Shimazaki J, Tsubota K. Tear cytokine and ocular surface alterations following brief passive cigarette smoke exposure. Cytokine. 2008; 43 (2): 200-208. doi: 10.1016/j.cyto.2008.05.011

[37] Ward SK, Dogru M, Wakamatsu T, Ibrahim O, Matsumoto Y, Kojima T, Sato EA, Ogawa J, Schnider C, Negishi K, Tsubota K. Passive cigarette smoke exposure and soft contact lens wear. Optom Vis Sci. 2010; 87 (5): 367-372. doi: 10.1097/OPX.0b013e3181d95188

[38] Agrawal N, Jharawal MK, Paharia N, Bansal K. Effect of smoking on ocular surface and tear film: A clinicopathological study. Adv Ophthalmol Vis Syst. 2018; 8 (6); 241-244. doi: 10.18689/mjop-1000112

[39] Erginturk Acar D, Acar U, Ozen Tunay Z, Ozdemir O, Germen $\mathrm{H}$. The effects of smoking on dry eye parameters in healthy women. Cutan Ocul Toxicol. 2017; 36 (1): 1-4. doi: $10.3109 / 15569527.2015 .1136828$

[40] Khalil HEM, Aboud SA, Azzab MA. Comparative study between smokers and nonsmokers regarding dry eye. Delta J Ophthalmol. 2018; 19 (1): 9-13. doi: 10.4103/DJO.DJO_25_17

[41] Agrawal N, Jharawal MK, Paharia N, Bansal K. Effect of smoking on ocular surface and tear film: a clinico pathological study. Madridge J Ophthalmol. 2018; 3 (1): 39-42. doi: 10.18689/mjop-1000112

[42] Altinors DD, Akça S, Akova YA, Bilezikçi B, Goto E, Dogru M, Tsubota K. Smoking associated with damage to the lipid layer of the ocular surface. Am J Ophthalmol. 2006; 141 (6): 1016-1021. doi: 10.1016/j.ajo.2005.12.047

[43] Yokoi N, Komuro A. Non-invasive methods of assessing the tear film. Exp Eye Res. 2004; 78 (3): 399-407. doi: 10.1016/j.exer.2003.09.020

[44] Rohit A, Brown S, Willcox M, Stapleton F. Evaluation of tear film lipid layer (TFLL) thickness and tear thinning rates in cigarette smokers. Invest Ophthalmol Vis Sci. 2014; 55 (13): 39 